\title{
Statistical analysis of severe magnetic fluctuations in the near-Earth plasma sheet observed by THEMIS-E
}

\author{
Heqiucen $\mathrm{Xu}^{1}$, Kazuo Shiokawa ${ }^{1}$, and Dennis Frühauff ${ }^{2}$ \\ ${ }^{1}$ Institute for Space-Earth Environmental Research, Nagoya University, Nagoya, Japan \\ ${ }^{2}$ Institut für Geophysik und extraterrestrische Physik, Technische Universität Braunschweig, Braunschweig, Germany \\ Correspondence to: Heqiucen Xu (xuheqiucen@isee.nagoya-u.ac.jp)
}

Received: 27 December 2016 - Revised: 12 August 2017 - Accepted: 22 August 2017 - Published: 9 October 2017

\begin{abstract}
We statistically analyzed severe magnetic fluctuations in the nightside near-Earth plasma sheet at 6-12 $R_{\mathrm{E}}$ (Earth radii; $1 R_{\mathrm{E}}=6371 \mathrm{~km}$ ), because they are important for non-magnetohydrodynamics (non-MHD) effects in the magnetotail and are considered to be necessary for current disruption in the inside-out substorm model. We used magnetic field data from 2013 and 2014 obtained by the Time History of Events and Macroscale Interactions during Substorms E (THEMIS-E) satellite (sampling rate: $4 \mathrm{~Hz}$ ). A total of 1283 severe magnetic fluctuation events were identified that satisfied the criteria $\sigma_{B} / \bar{B}>0.5$, where $\sigma_{B}$ and $\bar{B}$ are the standard deviation and the average value of magnetic field intensity during the time interval of the local proton gyroperiod, respectively. We found that the occurrence rates of severe fluctuation events are $0.00118,0.00899$, and $0.0238 \%$ at $6-8,8-10$, and $10-12 R_{\mathrm{E}}$, respectively, and most events last for no more than $15 \mathrm{~s}$. From these occurrence rates, we estimated the possible scale sizes of current disruption by severe magnetic fluctuations as $3.83 R_{\mathrm{E}}^{3}$ by assuming that four substorms with $5 \mathrm{~min}$ intervals of current disruption occur every day. The fluctuation events occurred most frequently at the $Z_{\mathrm{GSM}}(Z$ distance in the geocentric solar magnetospheric coordinate system) close to the model neutral sheet within $0.2 R_{\mathrm{E}}$. Most events occur in association with sudden decreases in the auroral electrojet lower (AL) index and magnetic field dipolarization, indicating that they are related to substorms. Sixty-two percent of magnetic fluctuation events were accompanied by ion flow with velocity $V>100 \mathrm{~km} \mathrm{~s}^{-1}$, indicating that the violation of ion gyromotion tends to occur during high-speed flow in the near-Earth plasma sheet. The superposed epoch analysis also indicated that the flow speed increases before the severe magnetic fluctuations. We discuss how both the inside-out and outside-in
\end{abstract}

substorm models can explain this increase in flow speeds before magnetic fluctuation events.

Keywords. Magnetospheric physics (plasma sheet; storms and substorms) - space plasma physics (kinetic and MHD theory)

\section{Introduction}

Substorms, which are important geomagnetic and auroral disturbances with timescales of 2 to $3 \mathrm{~h}$, were first identified by Akasofu (1964). The detailed description of substorms in that paper triggered a tremendous upsurge in related studies. Our understanding of substorms and their onsets has dramatically changed in the past few decades. As one approach to understand substorm onset, magnetic fluctuation is regarded as one possible instability to trigger substorms in the inner magnetosphere. Takahashi et al. (1987) reported strong magnetic fluctuations in the magnetotail at $|X|=8 R_{\mathrm{E}}$ (Earth radii; $1 R_{\mathrm{E}}=6371 \mathrm{~km}$ ). They showed magnetic field fluctuations in amplitudes from $10 \mathrm{nT}$ to more than $40 \mathrm{nT}$. Ohtani et al. (1995) pointed out that the typical timescale of these magnetic fluctuations is several times the proton gyroperiod. The research on magnetic fluctuations in the inner magnetosphere is accompanied by our progressing understanding of substorms.

After the identification of auroral substorms, many studies were conducted using ground-based magnetometers and allsky cameras. With the development of space technology, an increasing amount of satellite data has also become available for scientific research. Hones (1973) showed an important finding of both tailward and earthward plasma flows in the magnetotail, which suggests the formation of two magnetic 
neutral lines located near the Earth and far away in the tail. This study and related works formed the near-Earth neutral line (NENL) model of substorms (e.g., Baker et al., 1996; Shiokawa et al., 1997, 1998). Shiokawa et al. (1997, 1998) clarified the time sequence of substorm-related phenomena. From the appearance of a new $X$-type near-Earth neutral line, the eventual formation of a substorm current wedge resulted from earthward bursty bulk flow (BBF) and auroral initial brightening at the flow braking point. These ideas about the time sequences of substorm-related phenomena in the magnetotail eventually became the outside-in model.

Some researchers have focused on current disruption in the near-Earth tail rather than magnetic reconnection when exploring the origin of substorms (Lui, 2001). Lui et al. (1990) pointed out that kinetic cross-field instability can occur in the near-Earth tail before the substorm expansion phase. This instability can cause the formation of a substorm current wedge by reducing the cross-tail current. Lui (1991a, b) proposed a synthetic model in which instabilities in the nearEarth magnetotail may be the initial trigger of substorms. Some substorm-related features, including pseudo-breakups and the localized region of substorm initiation, could be explained by this model (Lui et al., 1991). These ideas came to be known as the inside-out model.

The formation of a new near-Earth neutral line (outside-in model) and current disruption in the near-Earth tail (insideout model) have become the two dominant approaches when considering substorm onset. Recognizing the importance of both down-tail and near-Earth activities may become a feasible approach in future studies (Henderson, 2009). For both of these two approaches, magnetic fluctuations in the nearEarth tail are involved as a phenomenon that requires more research. Ohtani et al. (1995, 1998) used Active Magnetospheric Particle Tracer Explorers/Charge Composition Explorer (AMPTE/CCE) data and fractal analysis to investigate substorm-related magnetic fluctuations, which are considered to be strongly related to plasma instabilities and current disruption. Ono et al. (2009) pointed out that during magnetic field dipolarization, ions in the near-Earth plasma sheet are non-adiabatically accelerated due to the induced electric field by these magnetic fluctuations. Nosé et al. (2010) revealed that dipolarization is accompanied by the appearance of magnetic fluctuations with a timescale of 3-5 s.

The importance of studying these magnetic fluctuations in the inner magnetotail also lies in the fact that they are strongly related to non-magnetohydrodynamics (non-MHD) processes in the magnetotail, during which the kinetic effect of ions plays an important role (Consolini et al., 2005). From the beginning of its development, MHD simulation has been a useful tool to study plasma in the magnetotail. Birn et al. (1996) used resistive MHD simulations to investigate the current disruption and diversion properties. By using a global MHD magnetosphere model, Wiltberger et al. (2000) unveiled many fast flow channels in the magnetotail with plasma and magnetic field properties that are

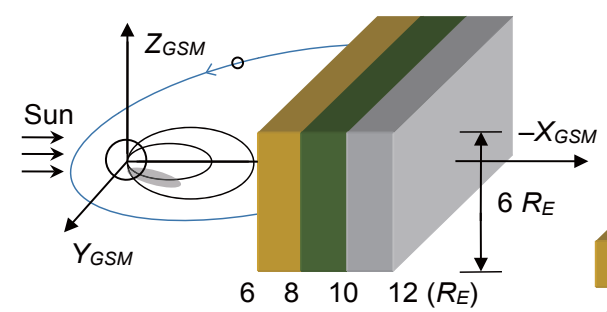

Region A

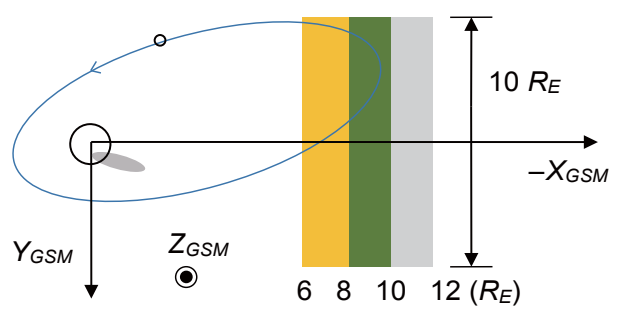

Region B

Figure 1. Three subregions chosen for analysis. The subregions are divided by GSM- $X$ coordinates. The top and bottom panels show the subregions in GSM coordinates and in the GSM- $X Y$ plane, respectively.

consistent with observations conducted by Angelopoulos et al. (1992). On the other hand, Lui and Najmi (1997) showed that during the current disruption, the spectrum of accompanied magnetic fluctuations becomes intermittently broad, covering timescales from below to above the ion gyroperiod. In such a particular circumstance, the collapse of the MHD condition causes continuous challenges for the study of magnetotail dynamics.

Despite the above various importance of magnetic field fluctuations for the dynamics of the magnetosphere, to our knowledge, there have been no comprehensive statistical analyses of magnetic fluctuations in the near-Earth plasma sheet. In this study, we conducted a statistical analysis of occurrence rate and substorm-related properties of severe magnetic fluctuations at periods shorter than the local ion gyroperiod in the near-Earth plasma sheet.

\section{Data set and method of analysis}

In this study, we used 2-year magnetic field data from 2013 and 2014 (sampling rate: $4 \mathrm{~Hz}$ ) obtained by the fluxgate magnetometer (FGM; Auster et al., 2008) aboard the Time History of Events and Macroscale Interactions during Substorms E (THEMIS-E) satellite (Angelopoulos, 2008). The plasma flow data were obtained by the electrostatic analyzer (ESA) aboard the same THEMIS-E satellite (McFadden et al., 2008). Figure 1 shows the region we chose for our analysis, which is located in the near-Earth tail at $(-9 \pm 3, \pm 5, \pm 3) R_{\mathrm{E}}$ in the geocentric solar magnetospheric (GSM) coordinate system. This region is most likely related to magnetic fluctuations that trigger substorms (e.g., Lui et al., 1991; Ohtani et al., 1995). Furthermore, we divided this 


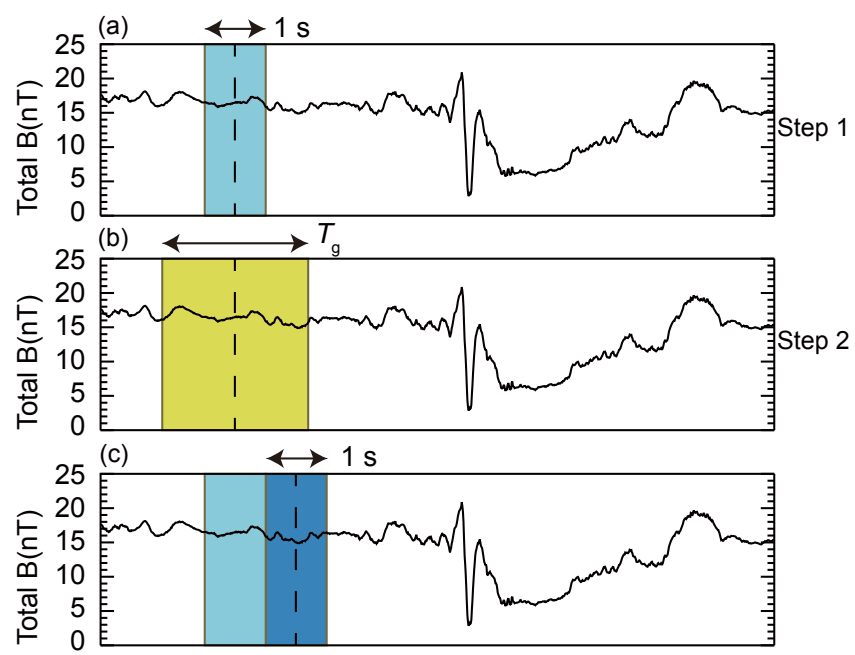

Figure 2. The two-step calculation to identify severe magnetic fluctuation events.

region into three subregions because we expected to observe some distance-related phenomena in the tail.

Figure 2 shows the two-step calculation we used to identify severe magnetic fluctuation events. In the first step, we calculated the average background magnetic field intensity $(B)$ for a $1 \mathrm{~s} \mathrm{time} \mathrm{interval} \mathrm{(shown} \mathrm{in} \mathrm{light} \mathrm{blue} \mathrm{rectangle} \mathrm{in}$ Fig. 2a). Then, we calculated the local gyroperiod of proton $T_{\mathrm{g}}$ as

$T_{\mathrm{g}}=\frac{2 \pi m_{\mathrm{p}}}{q B}$,

where $T_{\mathrm{g}}, m_{\mathrm{p}}$, and $q$ are the gyroperiod, mass, and charge of the proton, respectively (Chen, 1983; Nathaniel et al., 2015). In the second step, we calculated the ratio $R$ by

$R=\frac{\sigma_{B}}{\bar{B}}$,

where $\sigma_{B}$ and $\bar{B}$ are the standard deviation and average value of magnetic field intensity for the time interval $T_{\mathrm{g}}$ (shown as a yellow rectangle in Fig. 2b; Hendricks and Robey, 1936). This time interval $T_{\mathrm{g}}$ used in the second step was calculated by Eq. (1). Then we moved to the next adjacent $1 \mathrm{~s}$ time interval (shown as a dark blue rectangle in Fig. 2c) and applied the same two-step calculation. By repeating this calculation, those $1 \mathrm{~s}$ time intervals with $R>0.5$ in the second step were defined as severe magnetic fluctuation events. Note that we calculated the ratio $R$ based on every $1 \mathrm{~s}$ time interval from the original total magnetic field intensity data, and the time intervals of calculations in two steps (shown as a light blue rectangle in Fig. 2a and a yellow rectangle in Fig. 2b) had the same central time. Using this criterion, we focused on the magnetic fluctuations that violate ion gyromotion, which may cause ion kinetic effects such as current disruption at the substorm onset.

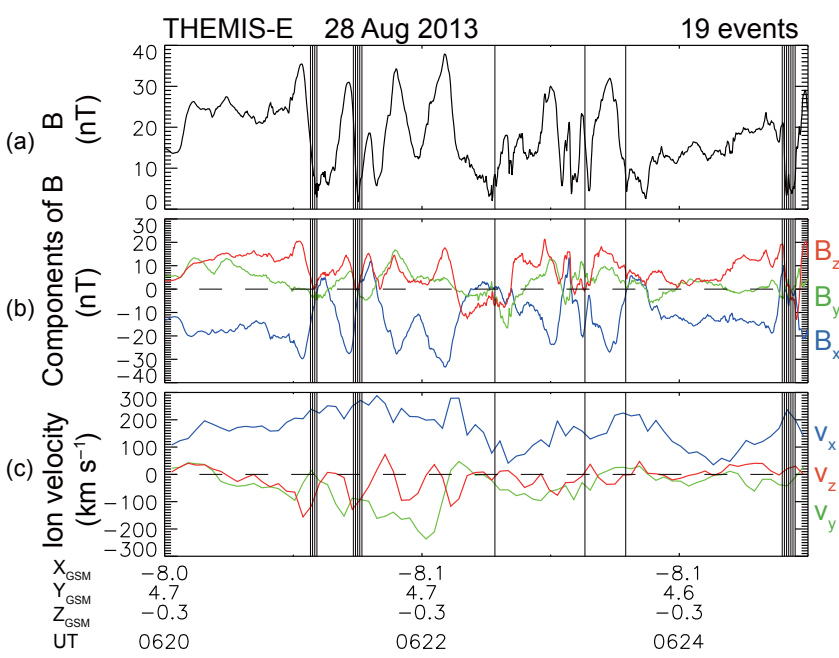

Figure 3. Example multiple-fluctuation events on 28 August 2013. There were 19 severe magnetic fluctuation events.

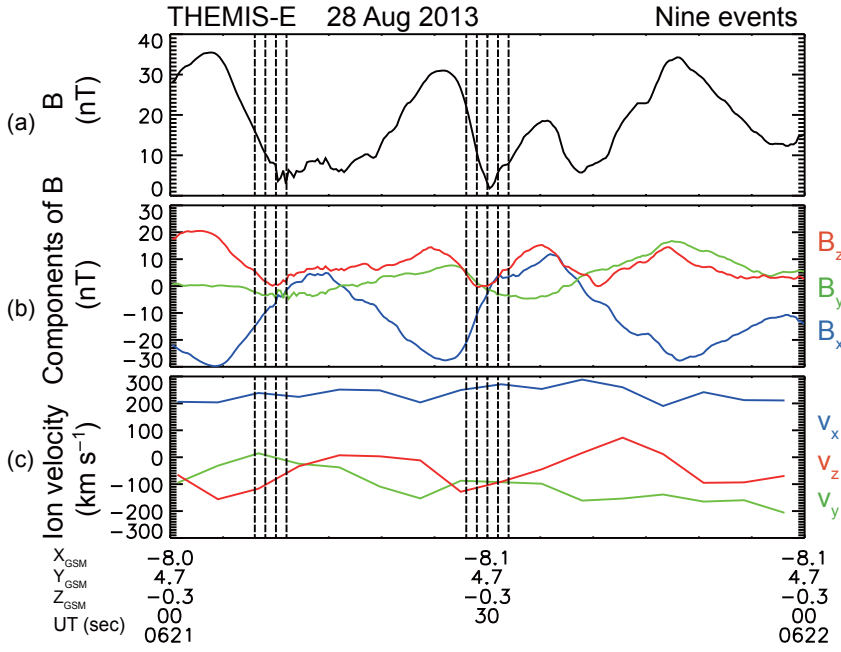

Figure 4. Enlarged plot for example multiple-fluctuation events on 28 August 2013. It shows the 1 min time interval after 06:21 UT. There were nine severe magnetic fluctuation events.

Since relatively long-lasting magnetic fluctuations are more relevant to substorm onset (Lui, 1991a), we defined three continuous severe magnetic fluctuation events that happen within $10 \mathrm{~min}$ as a multiple-fluctuation event. In our calculation of the background magnetic field intensity during the first step, we abandoned the sections with $B>65.5 \mathrm{nT}$ $\left(=2 \pi m_{\mathrm{p}} /\left(4 T_{\mathrm{s}}\right) q\right.$, where $T_{\mathrm{s}}=0.25 \mathrm{~s}$ is the sampling period of the magnetic field data) because we wanted to guarantee the reliability of the subsequent second step.

We should note that the present approach can include all kinds of magnetic fluctuations with large amplitudes comparable to or larger than the ambient magnetic field intensity and with periods shorter than the local ion gyroperiod. It can contain both incoherent structures, such as current disrup- 


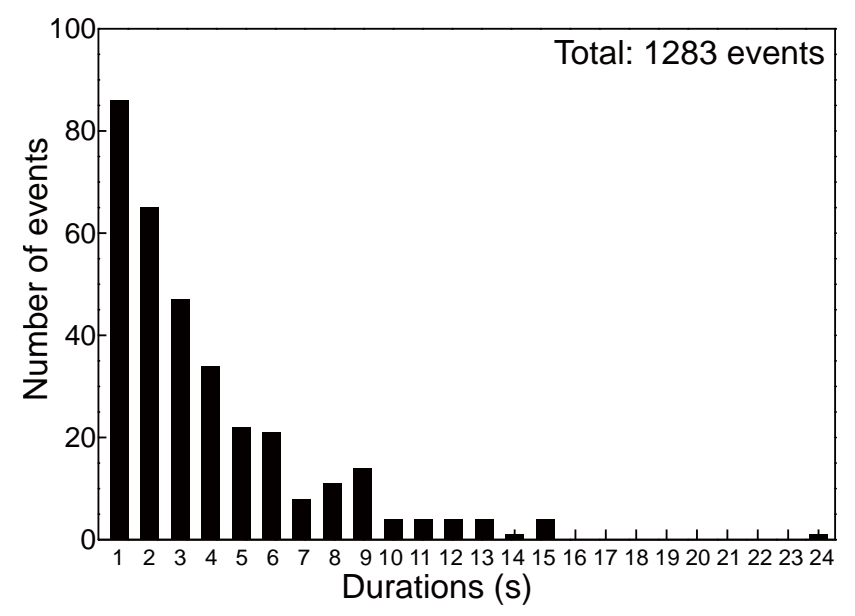

Figure 5. Distribution of duration time for severe magnetic fluctuation events.

tions caused by waves and instabilities, and coherent structures, such as sharp magnetic field change during dipolarization fronts (e.g., Runov et al., 2011) or the flapping of plasma sheet. Thus, the occurrence rates calculated by our criteria demonstrate the maximum values of the severe magnetic fluctuations caused by instabilities.

\section{Analysis and discussion}

\subsection{Fluctuation events and occurrence rate}

Figure 3 shows an example of 6 multiple-fluctuation events including 18 severe magnetic fluctuation events (the last severe magnetic fluctuation event in Fig. 3 was excluded). Note that the magnetic fluctuations occurred when the ion velocities were high. In order to show the property of severe magnetic fluctuation in more detail, we enlarged the $1 \mathrm{~min}$ time interval from 06:21 UT in Fig. 3, as shown in Fig. 4. There were nine severe magnetic fluctuation events during this 1 min time interval. The total magnetic field intensity shows a strong variation with an amplitude of $\sim 30 \mathrm{nT}$.

Our statistical analysis of the magnetic field intensity data from 2013 and 2014 yielded 1283 severe magnetic fluctuation events, among which there were 389 multiplefluctuation events containing 1167 severe magnetic fluctuation events. For all the severe magnetic fluctuation events, $1 \%$ of them are located in Region A, $19 \%$ of them are located in Region B, and $80 \%$ of them are located in Region C. For $99 \%$ of the severe magnetic fluctuation events, the plasma beta values were greater than 1 ( $21 \%$ were between 1 and 10 , and $78 \%$ were greater than 10), indicating that they were located in the plasma sheet (e.g., Baumjohann et al., 1990; Schmid et al., 2011).

Figure 5 shows the distribution of the duration time of these severe magnetic fluctuations. The duration was defined as the length of time during which the $1 \mathrm{~s}$ severe magnetic fluctuation events occurred sequentially. Nearly all fluctuations had duration times of less than $15 \mathrm{~s}$, with one exception (24s).

We estimated the occurrence rates of severe magnetic fluctuation events and multiple-fluctuation events for each subregion in the tail and for the entire region by calculating the ratio between the duration time of events and the total observation time taken for the corresponding region. For example, the occurrence rate of severe magnetic fluctuation events for Region A was calculated as $19 \mathrm{~s} / 1608118 \mathrm{~s}=0.00118 \%$. Table 1 shows the estimated occurrence rates for the three subregions. The occurrence rates of severe magnetic fluctuation events are $0.00118,0.00899$, and $0.0238 \%$ at $|X|=6-8$, $8-10$, and $10-12 R_{\mathrm{E}}$, respectively. The occurrence rates also show a tendency in decrease when the satellite location becomes closer to the Earth.

The occurrence rates of severe magnetic fluctuations calculated for multiple-fluctuation events are also shown in brackets in Table $1(0.114,0.620$, and $1.15 \%$ for Region A, Region B, and Region C, respectively). In this case, we utilized the $10 \mathrm{~min}$ time interval used in the definition of a multiple-fluctuation event as the numerator and the observation time of satellite as the denominator. We set the time of the first severe magnetic fluctuation event that belongs to one multiple-fluctuation event as the start time and accumulated the following $10 \mathrm{~min}$ time interval in the calculation of the occurrence rate. We removed the overlapped time interval between two adjacent multiple-fluctuation events (10 min time intervals).

Using these occurrence rates of severe magnetic fluctuation, we made two estimations. Firstly, magnetic fluctuation is considered as one possible trigger mechanism for current disruption and substorm onset in the inside-out substorm model. According to Borovsky et al. (1993), an average of four substorms occur every day. If we assume that all the substorms are accompanied by a 5 min current disruption (magnetic fluctuation with a duration time of $5 \mathrm{~min}$; e.g., Takahashi et al., 1987; Lui, 1991b), the ratio between the current disruption time $(5 \mathrm{~min} \times 4=20 \mathrm{~min})$ and the total time in a day $(1440 \mathrm{~min})$ is about $1.4 \%$. From Table 1 , we calculated the occurrence rate of severe magnetic fluctuations for the entire region $(0.0149 \%)$. Considering the inside-out substorm model, our results may indicate that approximately $1 \%(=0.0149 / 1.4)$ of all substorms are caused by severe magnetic fluctuations.

However, the above estimation of $1 \%$ contains the assumption that the current disruption occurs everywhere in the plasma sheet observed by the satellite. If we consider the possibility of localization of current disruption in a small region, which is more likely to occur, we would miss a lot of severe magnetic fluctuation events during the satellite measurement. Then if we assume that all the substorms are caused by the severe magnetic fluctuations, we can estimate the scale size of the current disruption region from 
Table 1. Occurrence rate and inferred volume of the onset region $(R>0.5)$.

\begin{tabular}{lrrrr}
\hline Region & $\begin{array}{r}\text { Number of events } \\
(\text { multiple events) }\end{array}$ & $\begin{array}{r}\text { Observation } \\
\text { time }(\mathrm{s})\end{array}$ & $\begin{array}{r}\text { Occurrence rate } \\
(\text { multiple events) }\end{array}$ & $\begin{array}{r}\text { Inferred } \\
\text { volume }\left(R_{\mathrm{E}}{ }^{3}\right)\end{array}$ \\
\hline Region A & 19 & 1608118 & $0.00118 \%$ & 0.30 \\
$\left(6-8 R_{\mathrm{E}}\right)$ & $(15)$ & & $(0.114 \%)$ & \\
Region B & 244 & 2714082 & $0.00899 \%$ & 2.31 \\
$\left(8-10 R_{\mathrm{E}}\right)$ & $(216)$ & & $(0.620 \%)$ & \\
Region $\mathrm{C}$ & 1020 & 4278838 & $0.0238 \%$ & 6.12 \\
$\left(10-12 R_{\mathrm{E}}\right)$ & $(936)$ & & $(1.15 \%)$ & \\
\hline
\end{tabular}

Table 2. Occurrence rate $(R>0.2)$.

\begin{tabular}{lrrr}
\hline Region & $\begin{array}{r}\text { Number of } \\
\text { events }\end{array}$ & $\begin{array}{r}\text { Observation } \\
\text { time }(\mathrm{s})\end{array}$ & $\begin{array}{r}\text { Occurrence } \\
\text { rate }\end{array}$ \\
\hline Region A $\left(6-8 R_{\mathrm{E}}\right)$ & 238 & 1608118 & $0.0148 \%$ \\
Region B $\left(8-10 R_{\mathrm{E}}\right)$ & 2566 & 2714082 & $0.0945 \%$ \\
Region C $\left(10-12 R_{\mathrm{E}}\right)$ & 9624 & 4278838 & $0.225 \%$ \\
\hline
\end{tabular}

the ratio between the occurrence rate of the observed severe magnetic fluctuations $(0.0149 \%)$ and the occurrence rate of substorms $(1.4 \%)$. The estimated scale size of current disruption is about $3.83 R_{\mathrm{E}}^{3}$ for the entire region (= $\left.6 R_{\mathrm{E}} \times 10 R_{\mathrm{E}} \times 6 R_{\mathrm{E}} \times 0.0149 / 1.4\right)$. This value seems to be a reasonable scale size for current disruption at substorm onset in the near-Earth plasma sheet, considering, for example, the scale size of bursty bulk flow $\left(2-3 R_{\mathrm{E}}\right.$ in the dawndusk direction and 1.5-2 $R_{\mathrm{E}}$ in the north-south direction; Nakamura et al., 2004). As shown in Table 1, similar estimations indicate that such localized volumes are $0.3 R_{\mathrm{E}}{ }^{3}$ (=2 $\left.R_{\mathrm{E}} \times 10 R_{\mathrm{E}} \times 6 R_{\mathrm{E}} \times 3 \times 0.00118 / 1.4\right)$ for Region A $\left(|X|=6-8 R_{\mathrm{E}}\right), 2.31 R_{\mathrm{E}}^{3}$ for Region $\mathrm{B}\left(|X|=8-10 R_{\mathrm{E}}\right)$, and $6.12 R_{\mathrm{E}}^{3}$ for Region $\mathrm{C}\left(|X|=10-12 R_{\mathrm{E}}\right)$.

In order to check the dependence of the occurrence rate of magnetic fluctuations on their amplitudes, we show the occurrence rate of magnetic fluctuation events by changing the selection criterion to $R>0.2$ in Table 2 . In this case, we obtained occurrence rates of fluctuation events nearly 10 times higher than those in Table 1 with $R>0.5$. This indicates that the occurrence of magnetic fluctuation events significantly decreases as their amplitudes become larger and approach the level to affect the ion gyromotion.

It should be noted that there is ambiguity in the relative locations of these fluctuation events with respect to the center of the plasma sheet in the $Z_{\mathrm{GSM}}$ direction. In the inside-out model, magnetic fluctuations that occur in the neutral sheet (that locate at the center of the plasma sheet) are regarded as one origin of current disruption (Lui et al., 1990). The estimation of the occurrence rate of substorm-related severe magnetic fluctuations would be affected by this ambiguity. In order to investigate this point, in the next subsection we calculated the distance from the model neutral sheet to the location of these fluctuation events.

\subsection{Distance to the T01-based neutral sheet}

We used the empirical Tsyganenko magnetospheric magnetic field model (T01) to evaluate the distance between fluctuation event locations and the varying neutral sheet (Tsyganenko, 2002a, b). This model is useful and valid at $|X| \leq$ $15 R_{\mathrm{E}}$ in the inner magnetosphere, which includes the region studied herein. We first defined the $Z_{\mathrm{GSM}}$ position of the neutral sheet as the location where the T01-based magnetospheric $B_{x}$ changes its sign for a given position $\left(X_{\mathrm{GSM}}\right.$, $\left.Y_{\mathrm{GSM}}\right)$. Then, we measured the $\Delta Z_{\mathrm{NS}}\left(Z_{\mathrm{GSM}}\right.$ distance from the satellite position to the neutral sheet) for each of the 1283 severe magnetic fluctuation events. We found that the values of $\Delta Z_{\mathrm{NS}}$ were less than $1 R_{\mathrm{E}}$ for all severe magnetic fluctuation events except for 38 excluded events due to the lack of solar wind data necessary for the T01 model. Next, we calculated the spatial distributions of the occurrence rates of severe magnetic fluctuation events in the GSM- $X Y$ and $X_{\mathrm{GSM}}-\Delta Z_{\mathrm{NS}}$ planes.

Note that in order to calculate the spatial distributions of the occurrence rates, we first needed to calculate $\Delta Z_{\mathrm{NS}}$ for all the observation time intervals from 2013 and 2014. To calculate the G1 and G2 parameters, which indicate the $1 \mathrm{~h}$ prehistory state of the solar wind in the T01 model, we used the solar wind and interplanetary magnetic field (IMF) data for 12 intervals of $5 \mathrm{~min}$ ( $1 \mathrm{~h}$ duration) before the observation times or event times and then calculated $1 \mathrm{~h}$ averages. However, for $9 \%$ of the observation times, valid solar wind or IMF data were not available, and we excluded those times. If the $5 \mathrm{~min}$ interval data were incomplete during the $1 \mathrm{~h}$ interval, we used the average of the 5 min interval data available to calculate the $\mathrm{G} 1$ and $\mathrm{G} 2$ parameters.

Figure 6 shows the spatial distributions of (a) the number of severe magnetic fluctuation events, (b) observation times when the satellite was in the given GSM- $X Y$ bin, and (c) the occurrence rates of the fluctuation events normalized by the observation times in the GSM- $X Y$ plane. The biggest occurrence rate $(0.1100 \%)$ locates at the dawn side at $|X|=11-$ $12 R_{\mathrm{E}}$, although the typical location of substorm dipolarization and bursty bulk flow in the tail is considered to be at 

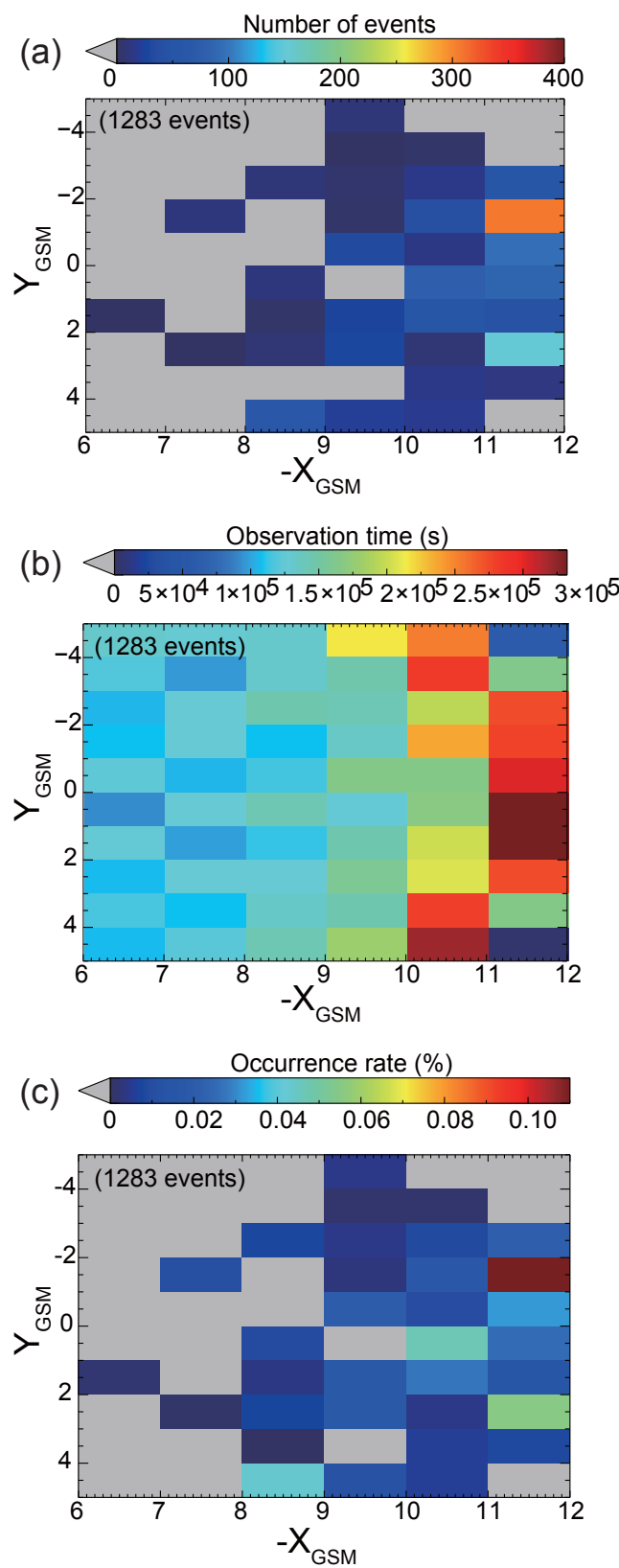

Figure 6. The spatial distribution of (a) the number of fluctuation events, (b) observation times when the satellite was in the given GSM- $X Y$ bin, and (c) the occurrence rates of the fluctuation events normalized by the observation times in the GSM- $X Y$ plane.

the dusk side of the tail (Nagai, 1991; Angelopoulos et al., 1994).

Figure 7 shows the spatial distributions of (a) the number of severe magnetic fluctuation events, (b) observation times, and (c) the occurrence rates of the fluctuation events normalized by the observation times in the plane of GSM- $X$ and $\Delta Z_{\mathrm{NS}}$. The biggest occurrence rate $(0.1105 \%)$ locates at $|X|=11-12 R_{\mathrm{E}}$, corresponding to a short distance to the neutral sheet at $\Delta Z_{\mathrm{NS}}<0.2 R_{\mathrm{E}}$. In this narrow region within
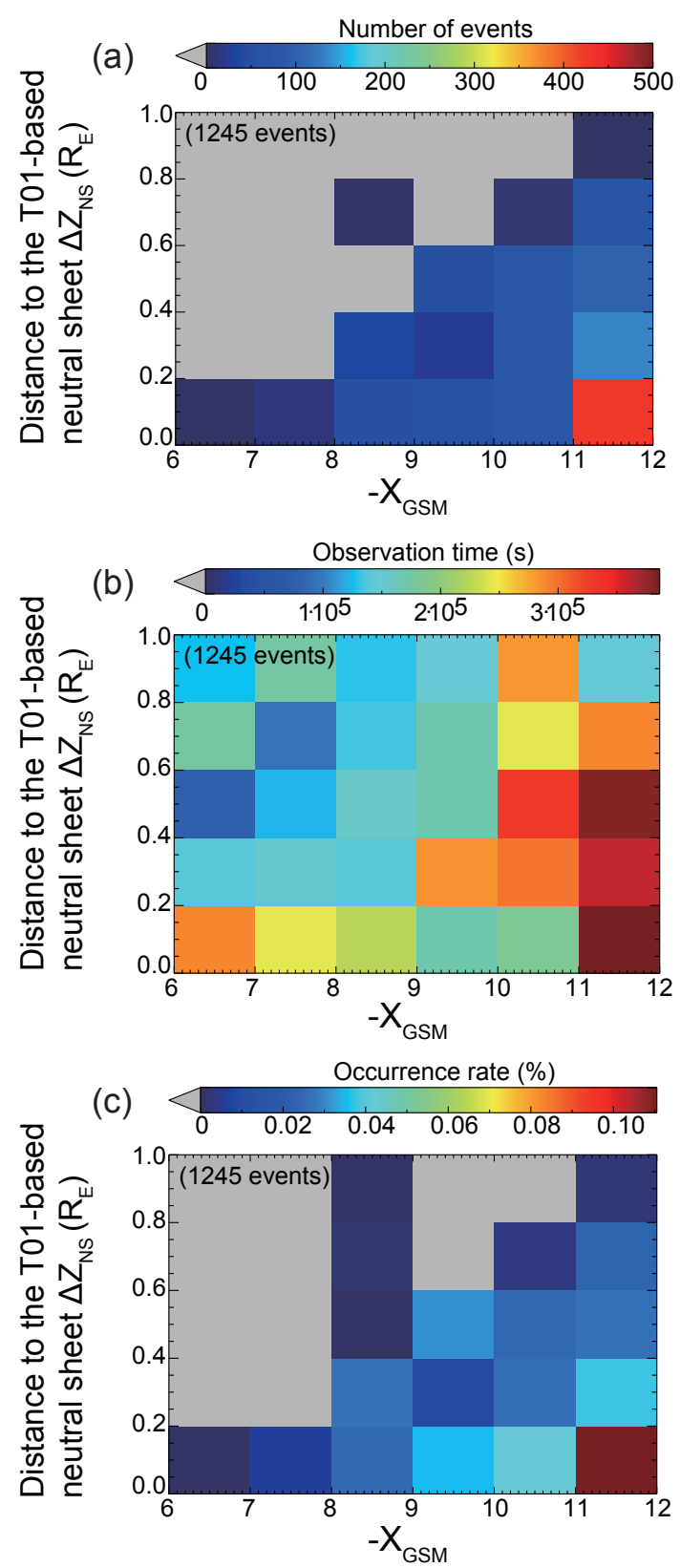

Figure 7. The spatial distributions of (a) the number of fluctuation events, (b) observation times, and (c) the occurrence rates of the fluctuation events normalized by the observation times in the GSM$X$ and $\triangle Z_{\mathrm{NS}}$ plane.

$1 R_{\mathrm{E}}$ of $\Delta Z_{\mathrm{NS}}$, the occurrence rate of severe magnetic fluctuation events tends to increase when it becomes closer to the neutral sheet. The occurrence rate of magnetic fluctuations is highest at the neutral sheet, which is consistent with the basic idea of the inside-out model.

Figure 8 shows the occurrence rates of severe magnetic fluctuation events with distance $\Delta Z_{\mathrm{NS}}$ to the neutral sheet for the three subregions. We found that they occur most fre- 


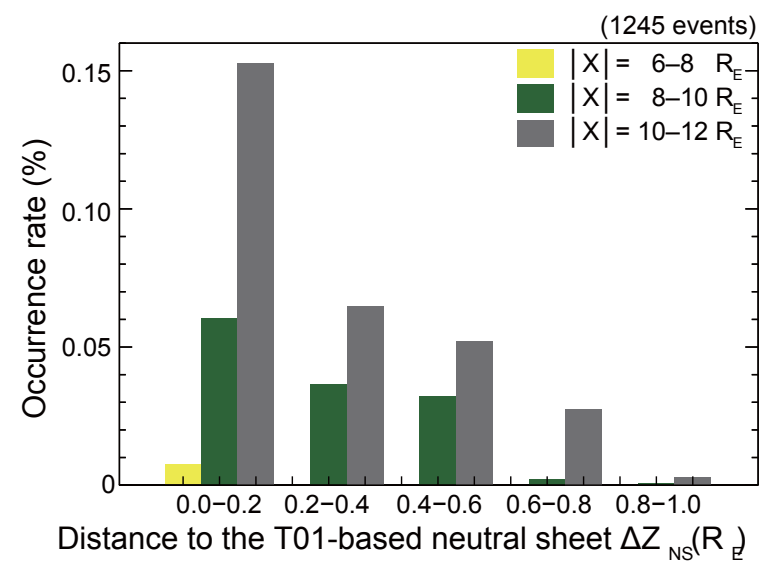

Figure 8. Occurrence rates of the fluctuation events with distance $\triangle Z_{\mathrm{NS}}$ to the neutral sheet for the three subregions.

quently in Region $\mathrm{C}\left(|X|=10-12 R_{\mathrm{E}}\right)$, and the highest occurrence rate in Region $\mathrm{C}$ is $0.1526 \%$ at $\Delta Z_{\mathrm{NS}}<0.2 R_{\mathrm{E}}$.

\subsection{Superposed epoch analysis of the AL index and magnetic field variations}

The auroral electrojet lower (AL) index is often used to indicate the occurrence of substorms (e.g, Shiokawa and Yumoto, 1993). In the calculation of the auroral electrojet (AE) index, the lower envelope of the north-south $H$-component perturbations observed at a series of stations near the auroral zone is named as the AL index (Davis and Sugiura, 1966). The $\mathrm{AL}$ index indicates the strength of the westward electrojet because westward current causes negative $H$-component perturbation. Nishida (1968) pointed out that there is no clear relationship between the $\mathrm{AE}$ index and substorm onsets, while the AL index is relatively closer to the substorm activity. Figure 9 shows the superposed epoch analysis of the AL index $1 \mathrm{~h}$ before and after the time of severe magnetic fluctuation events. A clear decrease in the AL index around the event time can be observed, suggesting that the fluctuation events occurred near the onset or during the expansion phase of substorms. This indicates that either (1) these severe magnetic fluctuation events are the cause of substorms, or (2) these magnetic fluctuations result from the substorms.

Figure 10 shows the superposed epoch analysis of magnetic field variations $1 \mathrm{~h}$ before and after the time of severe magnetic fluctuation events. A clear decrease in $\left|B_{x}\right|$ and an increase in $B_{z}$ after the fluctuation events are seen in Fig. 10b and $\mathrm{d}$, respectively. These results indicate magnetic dipolarization during the fluctuation events (e.g., Baumjohann et al., 1999; Shiokawa et al., 2005b).

Figure 10 also shows abrupt decreases in total $B,\left|B_{x}\right|$ and $B_{z}$ on a timescale of 1-2 min before the time of severe magnetic fluctuation events. We selected the fluctuation events with $\sigma_{B} / \bar{B}>0.5$. Thus, those magnetic fluctuations with a sudden decrease in the total magnetic field intensity would

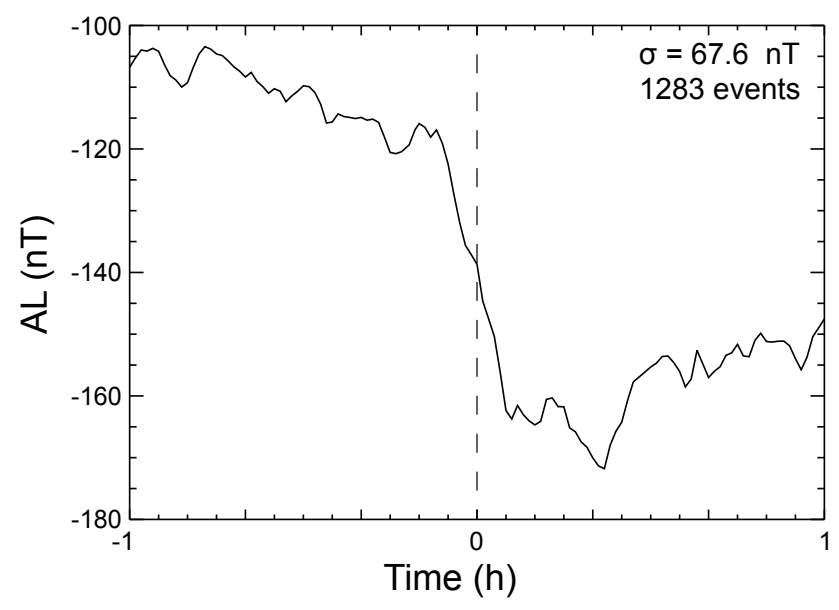

Figure 9. Superposed epoch analysis of the AL index $1 \mathrm{~h}$ before and after the time of severe magnetic fluctuation events.

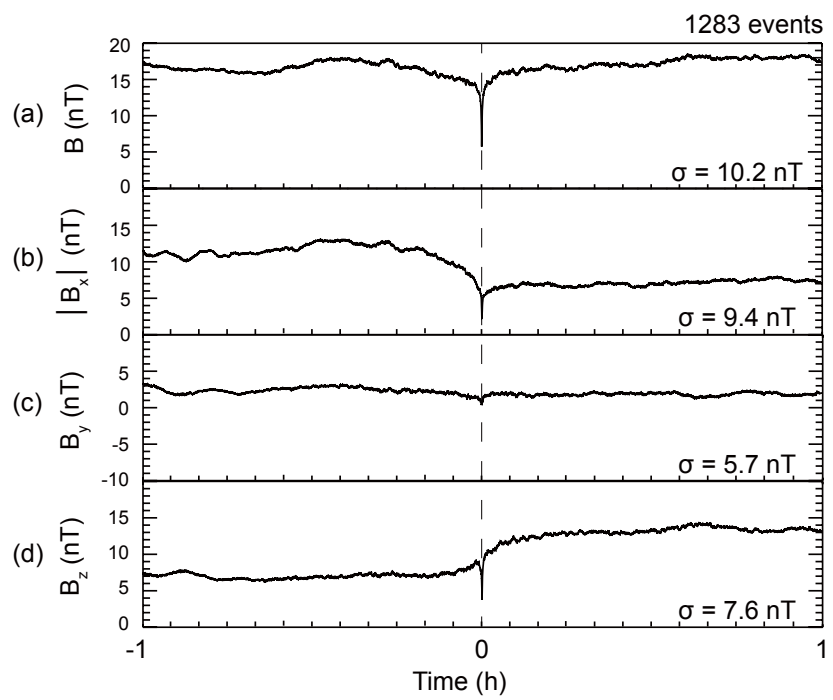

Figure 10. Superposed epoch analysis of magnetic field intensity variations $1 \mathrm{~h}$ before and after the time of severe magnetic fluctuation events.

be selected out easily. The decrease in $B_{z}$ at the time of dipolarization has been previously reported and was attributed to the explosive growth phase (Ohtani et al., 1992), magnetic flux ropes (Slavin et al., 2003), nightside flux transfer events (NFTEs; Sergeev et al., 1992), $B_{y}$ field accumulation at the flow front (Hashimoto et al., 2005), current disruption or substorm current wedge (Shiokawa et al., 2005b) and the dawnward currents because of reflection ions by the dipolarization front (Pan et al., 2015).

\subsection{Comparison with plasma flow data}

The relationship between magnetic fluctuation and fast plasma flows in the near-Earth plasma sheet has been previously studied (e.g., Bauer et al., 1995; Vörös et al., 2004; 


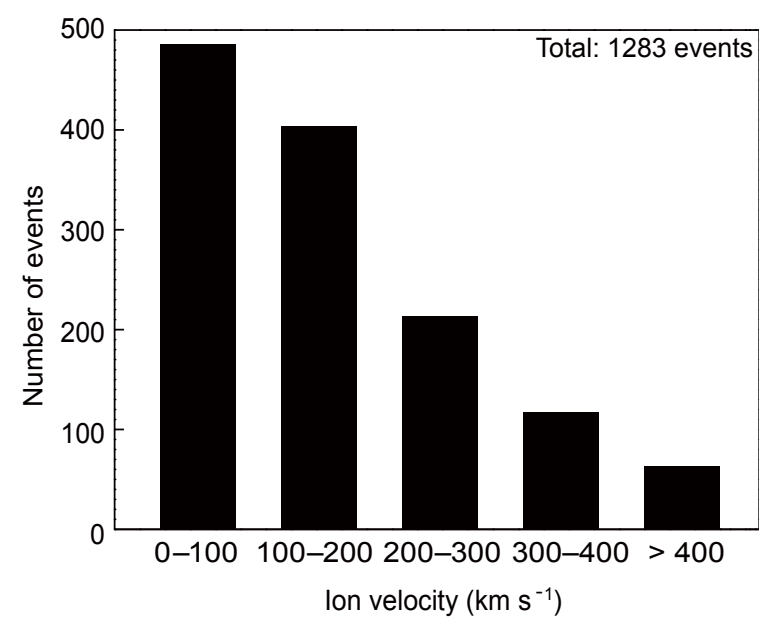

Figure 11. Distribution of $10 \mathrm{~s}$ averaged ion velocities during magnetic fluctuation events.

Shiokawa et al., 2005a). Using superposed epoch analysis, Frühauff and Glassmeier (2016) recently showed the characteristics of fast flows and related magnetic disturbances in the magnetotail. They revealed that during the entire flow burst timescale, the directions of minimum magnetic field variations are perpendicular to the main flow and the background magnetic field directions. In this section, in order to investigate the relationship between severe magnetic fluctuation events and high-speed ion flow, we compared magnetic fluctuation events with plasma data obtained by the THEMIS-E satellite. Figure 11 shows the distribution of $10 \mathrm{~s}$ averaged ion velocities $V$ at the time of all severe magnetic fluctuation events. We found that $62 \%$ of events are accompanied by ion flow with $V>100 \mathrm{~km} \mathrm{~s}^{-1}$. This fact indicates that the violation of ion gyromotion tends to occur during highspeed flow in the near-Earth plasma sheet. We also checked the sign of $V_{x}\left(V_{x}\right.$ is the $X$-component of ion velocity in the GSM coordinate system) and found that $77 \%$ of ion flows are earthward. These results suggest that either (1) the severe magnetic fluctuations are caused by high-speed ion flow, or (2) the fluctuations cause earthward ion flow by reducing the tailward pressure-gradient force due to current disruption, as suggested by the inside-out model. For case 2, the flow should be observed after the magnetic fluctuations.

Figure 12 shows the superposed epoch analysis of ion flow velocities $1 \mathrm{~h}$ before and after the time of severe magnetic fluctuation events. We can observe an increase in ion velocity from $\sim 10 \mathrm{~min}$ before the epoch time. This likely indicates that the high-speed ion flow causes the magnetic fluctuations (case 1).

To determine whether the magnetic fluctuation can cause the high-speed ion flow (case 2), we made some further adjustments. First, we calculated the average ion velocity at 0 $1 \mathrm{~min}$ before the time of severe magnetic fluctuation events and then selected those events with a 1 min averaged ion ve-

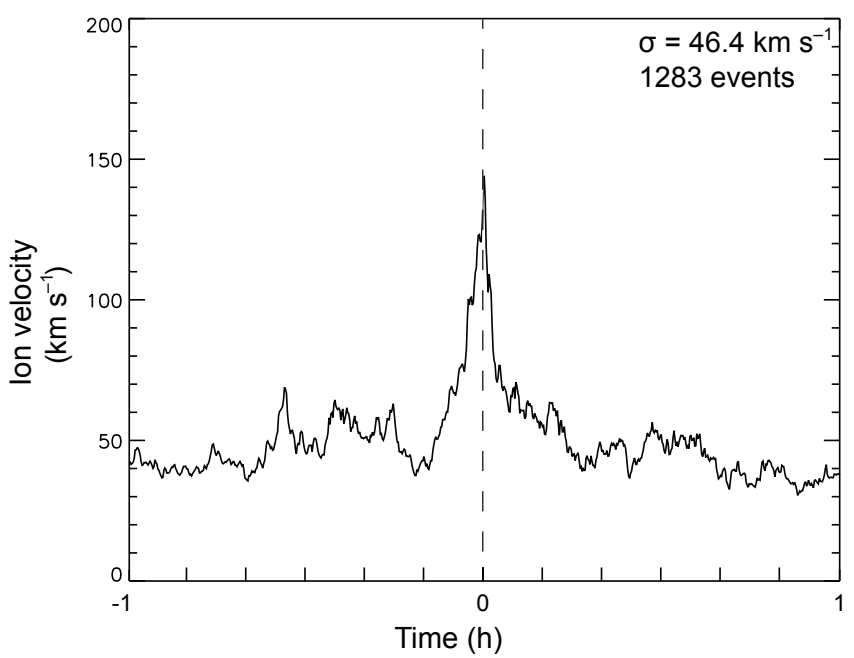

Figure 12. Superposed epoch analysis of ion velocity $1 \mathrm{~h}$ before and after the time of severe magnetic fluctuation events.

locity greater than the ion velocity at the event time. The superposed epoch analysis of ion velocity $1 \mathrm{~h}$ before and after the event time for the selected 698 events is shown in Fig. 13a, from which we can observe an increase in ion flow velocity before the event time. Figure $13 \mathrm{~b}$ shows the superposed epoch analysis for 303 selected events with an averaged velocity at $0-10 \mathrm{~min}$ before the event time greater than the velocity at the event time. Again, we cannot observe an increase in ion flow velocity after the event time.

Figure $13 \mathrm{c}$ and $\mathrm{d}$ are similar superposed epoch plots of ion velocity $1 \mathrm{~h}$ before and after the event time for those events with averaged ion velocities at $0-1$ and $0-10 \mathrm{~min}$ after the event time greater than the velocities at the event time, respectively. In these two plots, enhancements in ion flow velocity are observed after the event time. However, these events are fewer in number (only 118 and 70 events, respectively), and the amplitudes of the velocity enhancements are relatively small. As a result, Fig. 13a-c show clear increases in the ion velocity before the severe magnetic fluctuation events, which indicates that for most cases the severe magnetic fluctuations cannot be the cause of the high-speed plasma flow.

Here, we should further discuss the increase in plasma flow speed before the magnetic fluctuation. Before the present severe magnetic fluctuation event observed by the satellite, another current disruption (severe magnetic fluctuation) may occur at the tailward side of the satellite because the thinned plasma sheet can be unstable everywhere at the end of the growth phase of substorms. Then, the former current disruption can cause the observed increase in earthward plasma flow before the time of the present magnetic fluctuation event. However, we believe that such a possibility is unlikely because the earthward flow is generally accompanied by the dipolar magnetic field that stabilizes the plasma 

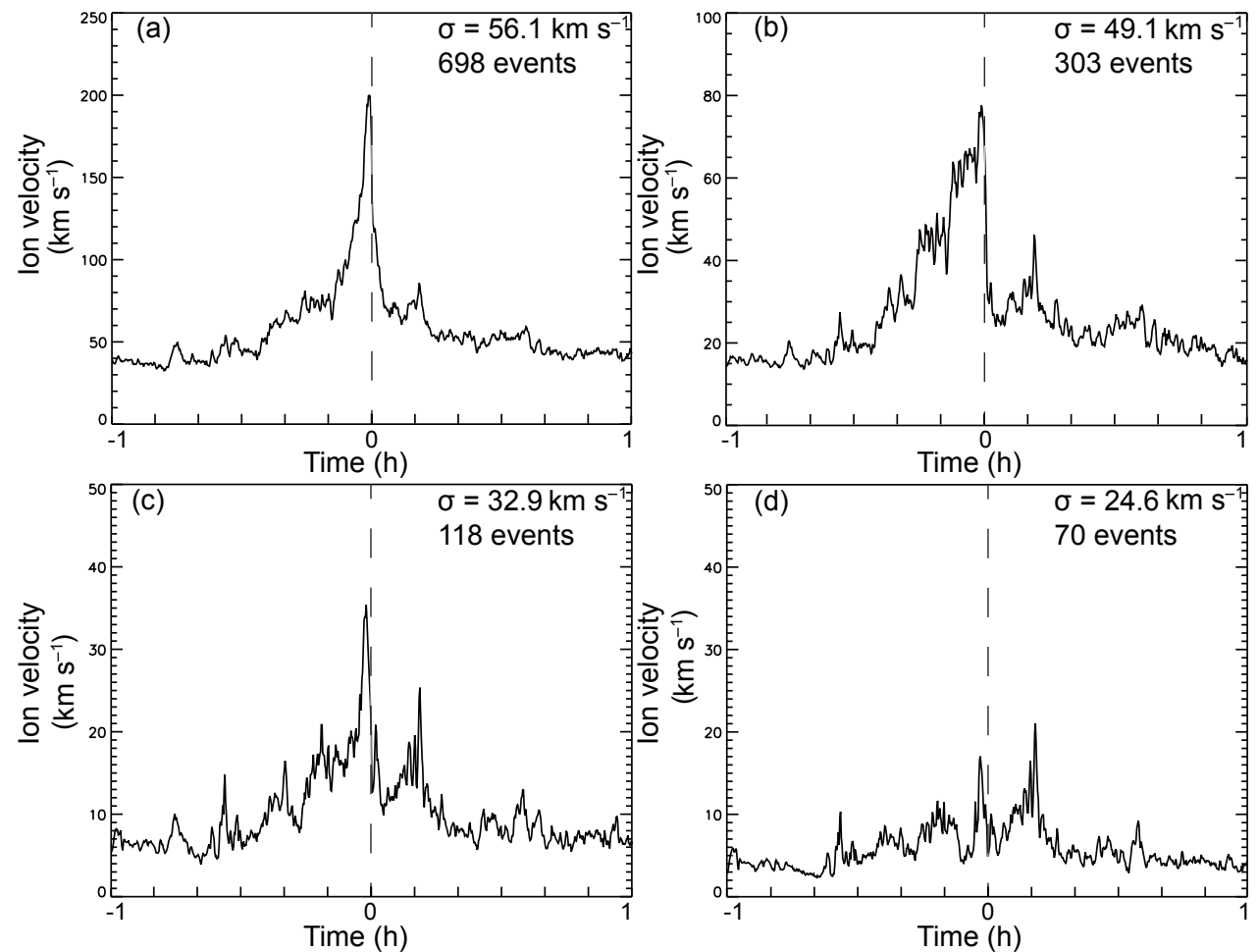

Figure 13. Superposed epoch analysis of ion velocity $1 \mathrm{~h}$ before and after the time of selected severe magnetic fluctuation events. In panel (a), we calculated the average of ion velocity at $0-1$ min before the event time and then selected those events with a 1 min averaged ion velocity greater than the ion velocity at the event time. Panels (b) to (d) show the superposed epoch analyses of ion velocity $1 \mathrm{~h}$ before and after the time of selected severe magnetic fluctuation events with similar methods by changing the time intervals of average value calculation into $10 \mathrm{~min}$ before, $1 \mathrm{~min}$ after, and $10 \mathrm{~min}$ after the event time.

instability due to the thinning of the plasma sheet. Thus, if the plasma instability that causes the current disruption is caused by the thinning of the plasma sheet, the present observation of flow enhancement before the magnetic fluctuation (current disruption) contradicts the idea that the earthward flow is caused by the current disruption.

On the contrary, another severe magnetic fluctuation may also occur at the earthward side of the satellite. The current disruption due to severe magnetic fluctuations can cause subsequent current disruptions to happen from the present site to more tailward locations, even without additional instabilities. That is, the earthward plasma flow associated with the current disruption causes depletion of the tailward pressure-gradient force at the site of the present plasma flow. This pressure decrease attracts plasma at the tailward side of the present location, causing the plasma to move earthward sequentially as a rarefaction wave (e.g., Haerendel, 1992; Hwang et al., 2014). Considering that the plasma flow can cause severe magnetic fluctuations, the possibility that the satellite detects the first current disruption (severe magnetic fluctuation) without plasma flow may become smaller. In that sense, we cannot deny the possibility that the current disruption in the inside-out model caused only the first earthward flow, and other earthward flows and associated severe mag- netic fluctuations occur subsequently. Then the number of the severe magnetic fluctuation events after the flow may become dominant, as observed in Figs. 12 and 13.

\section{Conclusions}

We used magnetic field data from 2013 and 2014 obtained by THEMIS-E at a sampling rate of $4 \mathrm{~Hz}$ to analyze severe magnetic fluctuation events. In total, 1283 severe magnetic fluctuation events were identified with $R=\sigma_{B} / \bar{B}>0.5$, where $\sigma_{B}$ and $\bar{B}$ are the standard deviation and the average value of magnetic field intensity during the time interval of the local proton gyroperiod. Ninety-nine percent of the fluctuation events had plasma beta values of more than 1 , indicating that they occurred in the plasma sheet. The results of the present study can be summarized as follows.

1. The occurrence rates of severe magnetic fluctuation events in the near-Earth plasma sheet $\left(|X|=6-12 R_{\mathrm{E}}\right)$ are $0.00118,0.00899$ and $0.0238 \%$ at $|X|=6-8,8$ 10 , and $10-12 R_{\mathrm{E}}$, respectively. Severe magnetic fluctuations occur most frequently in Region $\mathrm{C}(|X|=10$ $\left.12 R_{\mathrm{E}}\right)$. The durations of most fluctuation events are less than $15 \mathrm{~s}$. By assuming that four substorms with $5 \mathrm{~min}$ 
intervals of current disruption occur every day, we estimated the possible scale sizes of current disruption by severe magnetic fluctuations as $3.83 R_{\mathrm{E}}^{3}(0.3,2.31$, and $6.12 R_{\mathrm{E}}^{3}$ at $|X|=6-8,8-10$, and $10-12 R_{\mathrm{E}}$, respectively). We also found that the occurrence of magnetic fluctuation events significantly decreases as their amplitude becomes larger from $R>0.2$ to $R>0.5$.

2. We found that all the distances from the location of fluctuation events to the T01-based neutral sheet are less than $1 R_{\mathrm{E}}$. The bin with the highest occurrence rate of severe magnetic fluctuation events locates at $|X|=11$ $12 R_{\mathrm{E}}$ in the dawn side with a very close distance to the neutral sheet $\left(\Delta Z_{\mathrm{NS}}<0.2 R_{\mathrm{E}}\right)$. The occurrence rate is the highest at the neutral sheet, which is consistent with the basic idea of the inside-out model.

3. The superposed epoch analysis of the AL index $1 \mathrm{~h}$ before and after the time of severe magnetic fluctuation events shows an obvious decrease in index value around the event time. An increase in $B_{z}$ and a decrease in $\left|B_{x}\right|$ are observed during fluctuation events, indicating field dipolarization. These results suggest that the fluctuation events are related to the substorm onset or expansion phase. Temporal decreases in $B,\left|B_{x}\right|$, and $B_{z}$ on a timescale of 1-2 min before the time of severe magnetic fluctuation events are also observed.

4. Sixty-two percent of severe magnetic fluctuation events are accompanied by ion flow velocity with $V>$ $100 \mathrm{~km} \mathrm{~s}^{-1}$. This fact indicates that the violation of ion gyromotion tends to occur during high-speed flow in the near-Earth plasma sheet. The superposed epoch analysis of ion flow velocity from $1 \mathrm{~h}$ before to $1 \mathrm{~h}$ after the time of severe magnetic fluctuation events shows an increase in ion velocity before the event time. We discuss how both the inside-out and outside-in substorm models can explain this increase in flow speeds before magnetic fluctuation events.

Data availability. We used the IDL Geopack Dynamic Link Module (DLM) routines provided by $\mathrm{H}$. Korth to run the Tsyganenko magnetospheric magnetic field model. This model was developed by N. A. Tsyganenko (http://geo.phys.spbu.ru/ tsyganenko/ modeling.html). The OMNI data (http://omniweb.gsfc.nasa.gov) we used were obtained by SPEDAS/TDAS. We also used SPEDAS/TDAS to access the Dst and AL indices that were provided by the WDC for Geomagnetism, Kyoto University (http: //wdc.kugi.kyoto-u.ac.jp/).

Author contributions. HX conducted the analysis for this study and wrote the paper. KS guided this study as the graduate-course supervisor of HX. DF contributed to conducting this study as a coinvestigator of the THEMIS FGM. All authors have read and approved the final paper.
Competing interests. The authors declare that they have no conflict of interest.

Acknowledgements. We thank Vassilis Angelopoulos for his helpful suggestions and Yukinaga Miyashita for his support in SPEDAS/TDAS operation. We acknowledge support from the Leadership Development Program for Space Exploration and Research at Nagoya University. This work is supported by a Grantin-Aid for Scientific Research (JP 16H06286) from the Japan Society for the Promotion of Science. We acknowledge the NASA contract NAS5-02099 and V. Angelopoulos for the use of data from the THEMIS mission. We specifically acknowledge C. W. Carlson and J. P. McFadden for the use of ESA data and K. H. Glassmeier, U. Auster, and W. Baumjohann for the use of FGM data provided under the lead of the Technical University of Braunschweig and with financial support through the German Ministry for Economy and Technology and the German Center for Aviation and Space (DLR) under contract 50 OC 0302.

The topical editor, Georgios Balasis, thanks three anonymous referees for help in evaluating this paper.

\section{References}

Akasofu, S.-I.: The development of the auroral substorm, Planet. Space Sci., 12, 273-282, 1964.

Angelopoulos, V.: The THEMIS Mission, Space Sci. Rev., 141, 534, 2008.

Angelopoulos, V., Baumjohann, W., Kennel, C. F., Coronti, F. V., Kivelson, M. G., Pellat, R., Walker, R. J., Luehr, H., and Paschmann, G.: Bursty bulk flows in the inner central plasma sheet, J. Geophys. Res., 97, 4027-4039, https://doi.org/10.1029/91JA02701, 1992.

Angelopoulos, V., Kennel, C. F., Coroniti, F. V., Pellat, R., Kivelson, M. G., Walker, R. J., Russell, C. T., Baumjohann, W., Feldman, W. C., and Gosling, J. T.: Statistical characteristics of bursty bulk flow events, J. Geophys. Res., 99, 21257-21280, 1994.

Auster, H. U., Glassmeier, K. H., Magnes, W., Aydogar, O., Baumjohann, W., Constantinescu, D., Fischer, D., Fornacon, K. H., Georgescu, E., Harvey, P., Hillenmaier, O., Kroth, R., Ludlam, M., Narita, Y., Nakamura, R., Okrafka, K., Plaschke, F., Richter, I., Schwarzl, H., Stoll, B., Valavanoglou, A., and Wiedemann, M.: The THEMIS Fluxgate Magnetometer, Space Sci. Rev., 141, 235-264, 2008.

Baker, D. N., Pulkkinen, T. I., Angelopoulos, V., Baumjohann, W., and McPherron, R. L.: Neutral line model of substorms: Past results and present view, J. Geophys. Res., 101, 12975-13010, 1996.

Bauer, T. M., Baumjohann, W., Treumann, R. Sckopke, A., N., and Lühr, H.: Low-frequency waves in the near-Earth plasma sheet, J. Geophys. Res., 100, 9605-9617, 1995.

Baumjohann, W., Paschmann, G., and Lühr, H.: Characteristics of high-speed ion flows in the plasma sheet, J. Geophys. Res., 95, 3801-3809, https://doi.org/10.1029/JA095iA04p03801, 1990.

Baumjohann, W., Hesse, M., Kokubun, S., Mukai, T., Nagai, T., and Petrukovich, A. A.: Substorm dipolarization and recovery, J. Geophys. Res., 104, 24995-25000, https://doi.org/10.1029/1999JA900282, 1999. 
Birn, J. and Hesse, M.: Details of current disruption and diversion in simulations of magnetotail dynamics, J. Geophys. Res., 101, 15345-15358, https://doi.org/10.1029/96JA00887, 1996.

Borovsky, J. E., Nemzek, R. J., and Belian, R. D.: The occurrence rate of magnetospheric-substorm onsets: Random and periodic substorms, J. Geophys. Res., 98, 3807-3813, 1993.

Chen, F. F.: Introduction to Plasma Physics and Controlled Fusion, Plasma Physics, 2nd Edn., Plenum Press, Vol. 1, p. 20, ISBN 0306-41332-9, 1983.

Consolini, G., Kretzschmar, M., Lui, A. T. Y., Zimbardo, G., and Macek, W. M.: On the magnetic field fluctuations during magnetospheric tail current disruption: A statistical approach, J. Geophys. Res., 110, A07202, https://doi.org/10.1029/2004JA010947, 2005.

Davis, T. N. and Sugiura, M.: Auroral electrojet activity index AE and its universal time variations, J. Geophys. Res., 71, 785-801, https://doi.org/10.1029/JZ071i003p00785, 1966.

Frühauff, D. and Glassmeier, K. H.: Statistical analysis of magnetotail fast flows and related magnetic disturbances, Ann. Geophys., 34, 399-409, 2016.

Haerendel, G.: Disruption, ballooning or auroral avalanche - On the cause of substorms, in Proceedings of the International Conference on Substorms (ICS-1), Kiruna, Sweden 23-27 March 1992, Eur. Space Agency Spec. Publ., ESA SP-335, 417-420, 1992.

Hashimoto, C., TanDokoro, R., and Fujimoto, M.: Effects of guide field in three-dimensional magnetic reconnection, in: Frontiers in Magnetospheric Plasma Physics, COSPAR Colloq. Ser., edited by: Hoshino, M., Omura, Y., and Lanzerotti, L. J., Elsevier, New York, Vol. 16, 130-134, 2005.

Henderson, M. G.: Observational evidence for an inside-out substorm onset scenario, Ann. Geophys., 27, 2129-2140, https://doi.org/10.5194/angeo-27-2129-2009, 2009.

Hendricks, W. A. and Robey, K. W.: The Sampling Distribution of the Coefficient of Variation, Ann. Math. Stat., 7, 129-132, https://doi.org/10.1214/aoms/1177732503, 1936.

Hones Jr., E. W.: Plasma flow in the plasma sheet and its relation to substorms, Radio Sci., 8, 979-990, 1973.

Hwang, K.-J., Goldstein, M. L., Moore, T. E., Walsh, B. M., Baishev, D. G., Moiseyev, A. V., Shevtsov, B. M., and Yumoto, K.: A tailward moving current sheet normal magnetic field front followed by an earthward moving dipolarization front, J. Geophys. Res., 119, 5316-5327, https://doi.org/10.1002/2013JA019657, 2014.

Lui, A. T. Y.: A synthesis of magnetospheric substorm models, J. Geophys. Res., 96, 1849-1856, 1991a.

Lui, A. T. Y.: Extended consideration of a synthesis model for magnetospheric substorms, in: Magnetospheric Substorms, Geophys. Monogr. Ser., edited by: Kan, J. R., Potemra, T. A., Kokubun, S., and Iijima, T., AGU, Washington, DC, Vol. 64, 43-60, 1991b.

Lui, A. T. Y.: A multiscale model for substorms, Space Sci. Rev., 95, 325-345, 2001.

Lui, A. T. Y. and Najmi, A.-H.: Time-frequency decomposition of signals in a current disruption event, Geophys. Res. Lett., 24, 3157-3160, 1997.

Lui, A. T. Y., Mankofsky, A., Chang, C.-L., Papadopoulos, K., and Wu, C. S.: A current disruption mechanism in the neutral sheet: A possible trigger for substorm expansions, Geophys. Res. Lett., 17, 745-748, 1990.
Lui, A. T. Y., Chang, C.-L., Mankofsky, A., Wong, H.-K., and Winske, D.: A cross-field current instability for substorm expansions, J. Geophys. Res., 96, 11389-11401, 1991.

McFadden, J., Carlson, C., Larson, D., Bonnell, J., Mozer, F., Angelopoulos, V., Glassmeier, K.-H., and Auster, U.: THEMIS ESA First Science Results and Performance Issues, Space Sci. Rev., 141, 477-508, 2008.

Nagai, T.: An empirical model of substorm-related magnetic field variations at synchronous orbit, in: Magnetospheric Substorms, Geophys. Monogr. Ser., edited by: Kan, J. R., Potemra, T. A., Kokubun, S., and Iijima, T., AGU, Washington, DC, Vol. 64, $91-$ 95, 1991.

Nakamura, R., Baumjohann, W., Mouikis, C., Kistler, L. M., Runov, A., Volwerk, M., Asano, Y., Vörös, Z., Zhang, T. L., Klecker, B., Rème, H., and Balogh, A.: Spatial scale of high-speed flows in the plasma sheet observed by Cluster, Geophys. Res. Lett., 31, L09804, https://doi.org/10.1029/2004GL019558, 2004.

Nathaniel, E., Ukott, U., and Isaiah, U.: Analysis of Gyro-Period of Space Plasma Wave Using Interplanetary Magnetic Field Data, J. Appl. Phys., 7, 39-48, http://www.iosrjournals.org/iosr-jap/ papers/Vol7-issue3/Version-4/G07343948.pdf, 2015.

Nishida, A.: Geomagnetic DP2 fluctuations and associated magnetospheric phenomena, J. Geophys. Res., 73, 1795-1803, 1968.

Nosé, M., Koshiishi, H., Matsumoto, H., Brandt, P. C:son, Keika, K., Koga, K., Goka, T., and Obara, T.: Magnetic field dipolarization in the deep inner magnetosphere and its role in development of $\mathrm{O}^{+}$-rich ring current, J. Geophys. Res., 115, A00J03, https://doi.org/10.1029/2010JA015321, 2010.

Ohtani, S., Takahashi, K., Zanetti, L. J., Potemra, T. A., and McEntire, R. W.: Initial signatures of magnetic field and energetic particle fluxes at tail reconfiguration: Explosive growth phase, J. Geophys. Res., 97, 19311-19324, 1992.

Ohtani, S., Higuchi, T., Lui, A. T. Y., and Takahashi, K.: Magnetic fluctuations associated with tail current disruption: Fractal analysis, J. Geophys. Res., 100, 19135-19145, 1995.

Ohtani, S., Takahashi, K., Higuchi, T., Lui, A. T. Y., Spence, H. E., and Fennell, J. F.: AMPTE/CCE-SCATHA simultaneous observations of substorm-associated magnetic fluctuations, J. Geophys. Res., 103, 4671-4682, 1998.

Ono, Y., Nosé, M., Christon, S. P., and Lui, A. T. Y.: The role of magnetic field fluctuations in nonadiabatic acceleration of ions during dipolarization, J. Geophys. Res., 114, A05209, https://doi.org/10.1029/2008JA013918, 2009.

Pan, D.-X., Zhou, X.-Z., Shi, Q.-Q., Liu, J., Angelopoulos, V., Runov, A., Zong, Q.-G., and Fu, S.-Y.: On the generation of magnetic dips ahead of advancing dipolarization fronts, Geophys. Res. Lett., 42, 4256-4262, https://doi.org/10.1002/2015GL064369, 2015.

Runov, A., Angelopoulos, V., Zhou, X.-Z., Zhang, X.-J., Li, S., Plaschke, F., and Bonnell, J.: A THEMIS multicase study of dipolarization fronts in the magnetotail plasma sheet, J. Geophys. Res., 116, A05216, https://doi.org/10.1029/2010JA016316, 2011.

Schmid, D., Volwerk, M., Nakamura, R., Baumjohann, W., and Heyn, M.: A statistical and event study of magnetotail dipolarization fronts, Ann. Geophys., 29, 1537-1547, https://doi.org/10.5194/angeo-29-1537-2011, 2011.

Sergeev, V. A., Elphic, R. C., Mozer, F. S., Saint-Marc, A., and Sauvaud, J. A.: A two-satellite study of nightside flux transfer 
events in the plasma sheet, Planet. Space Sci., 40, 1551-1572, 1992.

Shiokawa, K. and Yumoto, K.: Global characteristics of particle precipitation and field-aligned electron acceleration during isolated substorms, J. Geophys. Res., 98, 1359-1375, https://doi.org/10.1029/92JA01092, 1993.

Shiokawa, K., Baumjohann, W., and Haerendel, G.: Braking of high-speed flows in the near-Earth tail, Geophys. Res. Lett., 10, 1179-1182, 1997.

Shiokawa, K., Baumjohann, W., Haerendel, G., Paschmann, G., Fennell, J. F., Friis-Christensen, E., Lühr, H., Reeves, G. D., Russell, C. T., Sutcliffe, P. R., and Takahashi, K.: High-speed ion flow, substorm current wedge, and multiple Pi 2 pulsations, J. Geophys. Res., 103, 4491-4507, 1998.

Shiokawa, K., Shinohara, I., Mukai, T., Hayakawa, H., and Cheng, C. Z.: Magnetic field fluctuations during substormassociated dipolarizations in the nightside plasma sheet around $X=10 \quad R_{\mathrm{E}}$, J. Geophys. Res., 110, A05212, https://doi.org/10.1029/2004JA010378, 2005a.

Shiokawa, K., Miyashita, Y., Shinohara, I., and Matsuoka, A.: Decrease in $\mathrm{Bz}$ prior to the dipolarization in the near-Earth plasma sheet, J. Geophys. Res., 110, A09219, https://doi.org/10.1029/2005JA011144, 2005b.
Slavin, J. A., Lepping, R. P., Gjerloev, J., Fairfield, D. H., Hesse, M., Owen, C. J., Moldwin, M. B., Nagai, T., Ieda, A., and Mukai, T.: Geotail observations of magnetic flux ropes in the plasma sheet, J. Geophys. Res., 108, 1015, https://doi.org/10.1029/2002JA009557, 2003.

Takahashi, K., Zanetti, L. J., Lopez, R. E., McEntire, R. W., Potemra, T. A., and Yumoto, K.: Distribution of the magnetotail current sheet observed by AMPTE/CCE, Geophys. Res. Lett., 14, 1019-1022, 1987.

Tsyganenko, N. A.: A model of the near magnetosphere with a dawn-dusk asymmetry: 1. Mathematical structure, J. Geophys. Res., 107, 1179, https://doi.org/10.1029/2001JA000219, 2002a.

Tsyganenko, N. A.: A model of the near magnetosphere with a dawn-dusk asymmetry: 2. Parameterization and fitting to observations, J. Geophys. Res., 107, 1176, https://doi.org/10.1029/2001JA000220, 2002b.

Vörös, Z., Baumjohann, W., Nakamura, R., Volwerk, M., Runov, A., Zhang, T. L., Eichelberger, H. U., Treumann, R., Georgescu, E., Balogh, A., Klecker, B., and Réme, H.: Magnetic turbulence in the plasma sheet, J. Geophys. Res., 109, A11215, https://doi.org/10.1029/2004JA010404, 2004.

Wiltberger, M., Pulkkinen, T. I., Lyon, J. G., and Goodrich, C. C.: MHD simulation of the magnetotail during the December 10, 1996, substorm, J. Geophys. Res., 105, 27649-27664, https://doi.org/10.1029/1999JA000251, 2000. 